DOI 10.37882/2223-2982.2021.08.18

\title{
МЕТОДЫ ОБУЧЕНИЯ ХИМИИ В СОВРЕМЕННОЙ ОБРАЗОВАТЕЛЬНОЙ СРЕДЕ: ВОЗМОЖНОСТИ И ПЕРСПЕКТИВЫ ${ }^{1}$
}

\section{METHODS OF LEARNING CHEMISTRY IN A MODERN EDUCATIONAL ENVIRONMENT: OPPORTUNITIES AND PROSPECTS ${ }^{2}$ \\ I. Kibalchenko T. Eksakusto}

Summary: The article is devoted to the study of methods of teaching chemistry and their preference by teachers of educational institutions in modern conditions. Interactive methods, project method and modeling as technology for teaching chemistry at school are described in this article. It is shown that these methods of development of conceptual thinking of schoolchildren are the basis for the assimilation of chemical knowledge. It has been suggested that chemistry teachers of educational institutions will differ in their preferences in choosing teaching methods: traditional and innovative. There was discovered a tendency, certifying that the developed conceptual abilities and chemical orientation of students mind is connected with teachers choise of modern methods of teaching chemistry (interactive methods, project methods, modeling of chemical objects). Research prospects are in the development and implementation of innovative teaching methods in a digital educational environment.

Keywords: teaching methods, interactive methods, project method, modeling, conceptual abilities, chemical orientation of the mind, older adolescents.
Кибальченко Ирина Александровна

Д.nсх.н., Институт компьютерных технологий и информационной безопасности - филиал Южного федерального университета (Таганрог)

kibal-irina@mail.ru

Эксакусто Татьяна Валентиновна

К.nсх.н., Институт компьютерных технологий и информационной безопасности - филиал Южного федерального университета (Таганрог) etv01@yandex.ru

Аннотация: Статья посвящена изучению методов обучения химии и их предпочтению учителями образовательных учреждений в современных условиях. Описаны интерактивные методы, метод проектов и моделирование как технологии обучения химии в школе. Показано, что данные методы могут способствовать развитию понятийного мышления школьников как основы усвоения химических знаний. Выдвинуто предположение о том, что учителя химии образовательных учреждений будут отличаться предпочтениями в выборе методов обучения: традиционных и инновационных. Обнаружена тенденция, свидетельствующая о том, что развитые понятийные способности и химическая направленность ума учащихся связана с выбором учителями современных методов обучения химии (интерактивных методов, метода проектов, моделирования химических объектов). Перспективы исследования состоят в разработке и внедрении инновационных методов обучения химии в цифровую образовательную среду.

Ключевые слова: методы обучения, интерактивные методы, метод проектов, моделирование, понятийные способности, химическая направленность ума, старшие подростки.

ния особых полимеров, которые используются в самолетостроении.

Необходимость освоения и разработки химических технологий в различных сферах предполагает наличие соответствующего кадрового потенциала, конкурентоспособного на рынке труда, готового к постоянному профессиональному росту, решению нестандартных задач в условиях дефицита времени и информации, принятию решений и т.д. Прежде всего, эти требования обращены к инженерам и молодым специалистам - выпускникам химических вузов. Наличие этого сегмента специалистов ставит задачу увеличения численности молодых людей средств до новых методов добычи нефти и газа; созда-

Исследование выполнено за счет гранта Российского фонда фундаментальных исследований (проект № 19-29-14019), Институт псИхолоГИи РАН.

2 The study was supported by a grant from the Russian Foundation for Basic Research (project No. 19-29-14019), Institute of Psychology, Russian Academy of Sciences. 
и подростков, выбирающих профессиональную направленность в области химии и химических технологий и подготовки их к поступлению в вуз.

Подготовка старшеклассников к поступлению на направления подготовки, связанные с химией и химическими технологиями, ставит перед образованием ряд актуальных вопросов, один из которых: эффективность методов обучения учащихся на уроках химии. Актуальность изучения методов обучения старшеклассников на уроках химии обусловлена и снижением естественнонаучной грамотности подрастающего поколения.

Известно, что ключевым фактором продуктивности мышления химика является понимание, познание химических процессов и взаимодействий химических элементов. То есть чем глубже и тоньше в учебном процессе отражается химическая форма движения материи, тем продуктивнее формирование химической направленности ума учащихся. Следовательно, развитие понятийных способностей учащихся является одной из главных задач повышения качества образования по химии.

В связи с этим возникает вопрос: какие методы обучения химии в большей степени будут способствовать развитию понятийных способностей и в итоге помогут старшеклассникам в эффективном усвоении химических знаний. Если классифицировать существующие методы обучения химии, то их можно разделить на две большие группы: традиционные и инновационные.

Безусловно, в школах преобладает использование традиционных методов обучения: объяснительно-иллюстративных и контролирующе-оценочных, что предполагает подачу информации для ее восприятия обучающимися и контроль знаний. Существенным недостатком этих методов является подача «готовой» информации (и не всегда в интересной для восприятия школьниками форме), которая предполагается к усвоению и запоминанию. В этом случае школьники становятся «потребителями» знаний, им не приходится использовать понятийные способности: анализировать, систематизировать, создавать новые идеи. Их пассивное восприятие информации приводит скорее к обратному эффекту, что снижает заинтересованность в предмете и ухудшает мотивацию к овладению достаточно сложными химическими знаниями. С учетом того, что в современный образовательный процесс активно внедряются цифровые технологии, использование традиционных объяснительно-иллюстративных методов становится еще более низко-эффективным, поскольку теряется контроль учителя над вниманием учеников.

Что касается инновационных методов, то они достаточно многообразны и по своим формам, и по обучающему воздействию $[1,10]$ на школьников. Остановимся на некоторых из них.

Интерактивные методы являются одной из самых больших групп инновационных методов, которые можно использовать в образовательном процессе. К ним относится групповая дискуссия, мозговой штурм, тренинговые технологии (в контексте метода химического эксперимента) и т.п. Интерактивное методы как специальная форма организации познавательной деятельности - это такой способ взаимодействия учителя и учащихся, в котором актуализируется развитие понятийных способностей учащихся, креативность, диалог культур [4, 9].

Групповая дискуссия является основным, опорным интерактивным методом в работе со школьниками. Основным этот метод становится потому, что предполагает, прежде всего, спонтанный, жестко не структурированный характер ведения обучения, недирективность поведения учителя. Групповая дискуссия дает возможность в свободной и комфортной атмосфере (без боязни и страха «быть вызванным») обсуждать определение понятий по изучаемому разделу химии; описывать признаки химических элементов; давать характеристики и сравнивать химические процессы; описывать химические ошибки; предлагать ассоциации, связанные с химическими процессами. Таким образом, групповая дискуссия может способствовать развитию семантических способностей школьников.

Мозговой штурм - метод решения проблемы на основе стимулирования творческой активности, при котором участникам обсуждения предлагают высказывать как можно большее количество вариантов решения задачи, а затем отбираются наиболее удачные. В результате проведения мозгового штурма, направленного, например, на определение оснований для разных классификаций химических понятий и элементов; структурирование материала по химии и т.п. у школьников развиваются категориальные способности, понимание эффективности принятия группового решения, понимание своей роли в процессе генарции идей.

Тренинговые технологии - совокупность различных приемов и способов организации активности личности, форма интерактивного обучения с целью научения чему-либо, развития различных компетенций. Технология тренингового занятия может включать систему заданий, организацию химического эксперимента, направленных на развитие большого количества умений и навыков, как узконаправленных (связанных с тренировкой навыков организации химического эксперимента), так и универсальных, способствующих становлению личности. В ходе тренинговой работы могут решаться такие задачи как: формулировка ключевых вопросов; формулировка противоречий и проблем при изучении химических явлений и процессов; прогнозирование проблем при 
планировании химических экспериментов; написание заключений по результатам выполнения работ, что способствует развитию у школьников концептуальных способностей.

Моделирование как инновационный метод - это метод опосредованного познания, при котором рассматривается модель изучаемого явления, находящаяся в определенном соответствии с познаваемым объектом, и дающая при ее исследовании новую информацию о моделируемом объекте. Технологию моделирования для обучения школьников химии можно использовать с разными целями: разработка химических сюжетов; формирование обобщенных знаний по химической номенклатуре; объяснение ресурсной роли химической грамотности в выборе профессии. Моделирование может способствовать развитию концептуальных способностей школьников.

Метод проектов - это способ достижения дидактической цели через детальную разработку проблемы (технологии), которая должна завершиться вполне реальным, документально оформленным практическим результатом - пояснительной запиской по проекту. В основе метода проектов лежит развитие познавательных навыков обучающихся, умений самостоятельно конструировать свои знания, умений ориентироваться в информационном пространстве, развитие критического и творческого мышления [6]. Метод проектов как интерактивная инновационная технология в обучении школьников химии может использоваться, например, с целью разработки и защиты авторских проектов по использованию химических соединений в различных сферах жизни человека; с целью обучения и консультирования своих сверстников по химии и др. Ценность этого метода заключается в том, что создание проекта способствует развитию категориальных, концептуальных и семантических способностей.

Современные исследования показывают, что предпочтение учителями в процессе обучения школьников химии интеграции интерактивного метода, метода проектов и моделирования химических объектов способствует:

- повышению уровня теоретических знаний, абстрактной мыслительной деятельности; формированию содержания понятий [8] и развитию понятийных способностей (семантических, категориальных и концептуальных);

- вовлечению учащихся в процесс познания, в котором освоение учебного материала сопровождается тем, что каждый участник вносит свой индивидуальный вклад в этот процесс;

- созданию условий для развития понятийного мышления через познание химических процессов и взаимодействий [7].
Таким образом, необходимость формирования у учащихся особого интереса к составу, свойствам и превращениям веществ, способности выделять из окружающего мира химические явления, химические закономерности и использовать их в реальной жизнедеятельности как элементов химической направленности ума, требует от учителей химии предпочтение именно инновационных методов обучения.

Содержание образования на уроках химии должно быть зримым, вещественным и затрагивать всю сенсорно-перцептивную организацию человека. Цель инноваций в выборе форм и методов обучения химии - научить учащихся реконструировать микромир химических взаимодействий посредством умственных моделей, в которых отражены особенности разных химических взаимодействий $[2,4]$.

Целью исследования стало изучение выбора методов обучения учителями химии общеобразовательных учреждений и их соотношение с уровнем развития понятийного мышления обучающихся.

В связи с этим мы предположили, что существуют различия в предпочтениях учителей в выборе методов обучения; существует количественная тенденция к взаимосвязи между предпочтениями учителей в выборе методов обучения и уровнем развития понятийных способностей обучающихся.

\section{Организашия исследования}

В исследовании участвовали учителя химии (31 человек) и учащиеся 8 классов общеобразовательных школ (140 человек).

Методы и методики, используемые в процессе эмпирического исследования: теоретическое изучение проблемы; обобщение и систематизация теоретических и экспериментальных исследований; анкетирование учителей; оценка понятийных семантических «Когнитивный состав концепта» (Холодная М.А.), категориальных «Обобщение трех слов» (Холодная М.А.) и концептуальных способностей «Понятийный синтез» (Холодная М.А.) на стимульном материале химии [3]; статистический критерий $\varphi^{*}$ «Угловое преобразование Фишера» для определения различий при сравнении диагностических результатов.

\section{Результаты исследования}

На первом этапе исследования учителям образовательных учреждений было предложено описать методы обучения, которые они используют в образовательном процессе. Описание строилось на основе классификации методов обучения как одного из основных параме- 
тров образовательной среды, В итоге были получены группы учителей, использующих разные методы обучения с предпочтительным выбором диады методов (Таблица 1). Общий полученный список методов включил следующие: объяснительно-иллюстративный; контрольно-оценочный; проблемный; исследовательский; метод химического эксперимента; метод проектов; моделирование химических объектов; интерактивный.

Полученные результаты таблицы (в группах 1, 2, 3) отражают предпочтения учителей (20 чел. - 66\%) в выборе репродуктивных методов обучения, хотя с тенденциями к интеграции с продуктивными методами (химический эксперимент, проблемный метод), занимающими второй ранг. Учителя групп 4 и 5 (11 чел. - 34\%), напротив, демонстрируют предпочтения в выборе диады продуктивных методов обучения. Необходимо отметить, что количество таких учителей меньше и значимо отличается от количества учителей 1-3 групп: $\varphi^{*} э$ мп. $=2,315, \varphi^{*}$ кр. $=2,31$, $\mathrm{p} \leq 0,01$. Обращает на себя внимание выбор учителями традиционных технологий обучения, что уже на данном этапе демонстрирует необходимость специальной просветительской и коррекционной работы с педагогами, направленной на развитие и совершенствование навыков использования инновационных методов обучения.

На втором этапе исследования были получены диагностические показатели сформированности понятийного мышления учащихся в понятийном поле химии: значение показателя - «точность словесных ассоциаций» (подбора признаков) по методике «Когнитивный состав» (по шкале баллов - 0, 1, 2, 3); значение показателя уровня обобщения (тематического, аналитического, категориального или проникновения в сущность явления) по методике «Категориальное обобщение» (обобщение 3-х слов по шкале баллов - 0, 1, 2, 3); значение показателя теоретического анализа изучаемых терминов по методике «Понятийный синтез» (по шкале баллов - 0, 1, 2, 3).
Например, по методике «Когнитивный состав концепта «Химические реакции»»: получены ответы, включающие от 1-2 до 20 признаков, отражающих уровневую (по шкале баллов - 0, 1, 2, 3) осведомленность учащихся о составе концепта, актуализированных аспектов и модальностей концепта (ухудшающих или уточняющих его содержание). В итоге были получены характеристики когнитивных структур знаний: от «плохая, простая, сложная» $(0$ - 1 балл) до «химическая связь в различных веществах, реакции соединения, реакции разложения и обмена» (2 балла) и до «ионная, ковалентная, ковалентная неполярная и полярная связь, процесс образования разных видов связи, скорость химической реакции, типы химических реакций, признаки протекания реакций изменение цвета, выпадение осадка, выделение газов, образование соединений, излучение и т.п. (3 балла).

По методике «Понятийный синтез» учащимся было предложено установить разные варианты смысловых связей в виде 1-2 предложений со словами «спирт - кислота - вода». Примеры уровневых ответов: «0 баллов нет ответа»; «1 балл - На полке стояли спирт, кислота и вода» (связь на основе простого перечисления; «2 балла - Для опыта на уроке химии учитель подготовил кислоту, спирт и воду» (все три слова включены в определенную конкретную ситуацию); «3 балла - Смешав спирт с водой, получили водку, которая сгубила больше людей, чем любая кислота» (объединение трех слов за счет использования сложных аналогий и причинно-следственных связей).

По теме «Галогены» по методике «Категориальное обобщение» (обобщение 3-х слов «фтор, хлор, бром») были предложены разноуровневые ответы: «0 баллов Опасные вещества» (тематическое обобщение на основе ассоциативных связей); «1 - Простые вещества» (аналитическое обобщение на основе конкретного признака); «2 - галогены» (категориальное обобщение); «3 - Химические элементы группы «галогены» с выраженными

Распределение учителей химии по предпочтениям в выборе методов обучения

\begin{tabular}{|c|c|c|c|}
\hline Группы & Предпочтительная диада методов & Содержание методов & Кол-во учителей (в \%) \\
\hline 1 & $\begin{array}{l}\text { Объяснительно-иллюстративный и } \\
\text { контролирующе-оценочный }\end{array}$ & $\begin{array}{l}\text { Подача готовой информации для ее восприятия обучающимися, } \\
\text { контроль знаний }\end{array}$ & 23 \\
\hline 2 & $\begin{array}{l}\text { 0бъяснительно-иллюстративный и } \\
\text { метод химического эксперимента }\end{array}$ & $\begin{array}{l}\text { Подача готовой информации и обучение делать выводы, доказы- } \\
\text { вать, обосновывать и защищать идеи (эксперимент посредством } \\
\text { видеоматериалов) }\end{array}$ & 20 \\
\hline 3 & $\begin{array}{l}\text { 0бъяснительно-иллюстративный и } \\
\text { проблемный метод }\end{array}$ & $\begin{array}{l}\text { Подача готовой информации и усвоение способа и логики решения } \\
\text { проблемы, но еще без способности применять их самостоятельно }\end{array}$ & 23 \\
\hline 4 & $\begin{array}{l}\text { Интерактивный (от «interactive» - «вза- } \\
\text { имодействующий») и метод проектов }\end{array}$ & $\begin{array}{l}\text { Развитие интеллектуальных способностей учащихся через усвое- } \\
\text { ние алгоритма научного исследования }\end{array}$ & 20 \\
\hline 5 & $\begin{array}{l}\text { Интеракивный и моделирование хими- } \\
\text { ческих объектов }\end{array}$ & $\begin{array}{l}\text { Развитие понятийного мышления через познание особенностей } \\
\text { разных химических взаимодействий }\end{array}$ & 14 \\
\hline
\end{tabular}


свойствами неметаллов» (проникновение в сущность явления).

Полученные результаты учащихся 8 классов отражают уровень ниже среднего сформированности у них семантических способностей $(1,1)$ по методике «Когнитивный состав концепта», уровень ниже среднего категориальных способностей $(0,83)$ по методике «Обобщение трех слов», уровень ниже среднего концептуальных способностей $(1,2)$ по методике «Понятийный синтез». Полученные результаты отражают устойчивость низкого уровня сформированности понятийных способностей учащихся в целом. Однако в процессе работы выделилась группа учащихся (36 человек - 26\%) с более высокими показателями понятийных способностей. А именно: средний уровень семантических способностей $(2,16)$; тенденция к среднему уровню категориальных способностей $(1,61)$; тенденция к среднему уровню концептуальных способностей $(1,5)$. Эта группа учащихся по количеству значимо отличается от общей выборки учащихся 8 классов: $\varphi^{*} э м п=8.492, \mathrm{p} \leq 0,01$.

Полученные результаты позволяют сделать вывод о несформированности у учащихся понятийных способностей в понятийном поле химии: трудности переработки семантической информации и подбора признаков, соответствующих химических понятиям и процессам; трудности в выделении скрытых (едва различимых) признаков в химических понятиях, в установлении связи между этими понятиями; трудности в нахождении сложного контекста, объединяющего и заданные понятия, и самостоятельно дополненные учащимися. Таким образом, обнаруживается противоречие между тем, что для развития понятийного мышления необходимо использовать инновационные методы обучения, направленные на развитие понятийных способностей учащихся, и неготовностью учащихся решать нестандартные задачи [5].

В отдельных исследованиях [2] показано, что существует прямая связь между уровнем развития химической направленности ума у преподавателей, их предпочтениями в выборе методов обучения и уровнем развития понятийных способностей в понятийном поле химии обучающихся. Сравнивая распределение учителей химии по предпочтениям в выборе методов обучения (66\% использующих традиционные методы и 34\% - инновационные) и распределение учащихся с низким уровнем понятийных способностей и уровнем понятийных способностей с тенденцией к среднему (74\% и 26\%), не получено значимых различий $\left(\varphi^{*} э м п .=0,156\right)$ между этими распределениями. Вероятно, одной из объяснительных причин отсутствия достоверных различий является недостаточная разработанность инновационных методов для преподавания химии в школе, что определяет необходимость создания таких технологий и их апробации в условиях преподавания химии. Однако, несмотря на отсутствие достоверных различий, обнаруживается тенденция, подтверждающая высказанное мнение о соотношении распределения предпочтений в выборе методов обучения учителями химии и распределением уровней развития понятийных способностей обучающихся в проблемном поле химии: традиционные методы обучения не способствуют развитию понятийных способностей.

\section{Зак^ючение}

Теоретически и эмпирически выявлены тенденции в использовании методов обучения химии: обнаружены различия в предпочтениях учителей в выборе методов обучения (значимо чаще учителя отдают предпочтения объяснительно-иллюстративному методу в сочетании с химическим экспериментом и проблемным методом); эмпирически выделена группа учителей химии, отдающих предпочтение интеграции интерактивного метода с методом проектов и моделированием химических объектов, направленных на повышение уровня теоретических знаний, абстрактной мыслительной деятельности, формирование содержания понятий по химии.

На уровне тенденций обнаружена взаимосвязь между предпочтениями в выборе методов обучения учителями химии и признаками развития понятийных способностей обучающихся в понятийном поле химии.

В качестве ведущих принципов в организации образовательной среды и рекомендаций по химии выделены использование моделирования, методов проекта и методов интерактивного обучения, направленных на создание атмосферы взаимной поддержки, развитие толерантности к неопределенности, принятие совместного решения, описание признаков химических элементов и химических ошибок, включение учащихся в проектную деятельность, формирование обобщенных знаний по химической номенклатуре, объяснение ресурсной роли химической грамотности в выборе профессии, разработку и защиту авторских проектов по химии и др.

Перспективой исследования является разработка и внедрение инновационных технологий, максимально вовлекающих учащихся в процесс изучения химии, а также включение этих методов обучения в цифровую образовательную среду для развития осознанной значимости и эмоциональной привлекательности процесса преподавания химии. В связи с этим актуален анализ работы учителей химии, использующих в образовательном процессе интерактивные, проектные технологии, технологии моделирования с точки зрения возможности их использования в дистанционном формате. Необходима разработка критериев оценки деятельности и усвоения старшеклассниками химических знаний в условиях цифровой среды. 


\section{ЛИТЕРАТУРА}

1. Бекирова Р.С., Рыков С.П. Интерактивные технологии обучения в контексте компетентностного подхода в образовании // Проблемы социально-экономического развития Сибири, 2010, - №1. С. 70 - 84. URL: https://www.elibrary.ru/item.asp?id=16550073

2. Волкова Е.В. Психология специальных способностей: дифференционно-интеграционный подход [монография] / Е.В. Волкова. М.: Изд-во «Институт психологии РАН», 2011. - 319 с. ISBN 978-5-9270-0210-8

3. Волкова Е.В. Общий универсальный закон развития, развитие когнитивных структур химического знания и химические способности [монография] / Е. В. Волкова. - Екатеринбург : Изд-во Уральского ун-та, 2008. - 511 с. ISBN 978-5-7996-0374-8

4. Волкова Е.В. Химическая направленность ума // Химия в школе. 2008. № 2. С. 2-7. URL: https://www.elibrary.ru/item.asp?id=9917885

5. Еремин В.В. Элементы научного поиска при решении нестандартных задач по химии // Современные тенденции развития химического образования: работа с одаренными школьниками. Сборник под общей ред. акад. В.В. Лунина. М.: Изд-во Моск. ун-та, 2007. С. 114-121.

6. Кибальченко И.А., Истратова 0.Н., Эксакусто Т.В. Рефлексивно-интегративный подход к подготовке современного педагога в многоуровневой системе непрерывного образования //Подготовка современного педагога в многоуровневой системе непрерывного образования: коллективная монография / под ред. В. К. Шаповалова, И. Ф. Игропуло. - Ставрополь: Изд-во СКФУ, 2015. - С. 3-26.

7. Музаева, 3.М. Интерактивные методы преподавания химии в современной школе // Инновационные педагогические технологии: материалы III Междунар. науч. конф. (г. Казань, октябрь 2015 г.). - Казань: Бук, 2015. - С. 20-24. - URL: https://moluch.ru/conf/ped/archive/183/8943/.

8. Перминова Л.М. Формирование общих учебных умений общего образования - СПб,: АППО, 2006. - 313с.

9. Примерные программы по учебным предметам. Химия. 10-11 классы: проект. - М.: Просвещение, 2010. - 88 с. - (стандарты второго поколения). ISBN 978-5-09-024306-3.

10. Титова Г.С. Интерактивные технологии, их виды и роль в контуре современного высшего образования//Wschodnioeuropejskie Czasopismo Naukowe (East European Scientific Journal). - №7, 2016 C. 68-70. URL: https://www.elibrary.ru/item.asp?id=28183696

(c) Кибальченко Ирина Александровна (kibal-irina@mail.ru), Эксакусто Татьяна Валентиновна (etv01@yandex.ru).

Журнал «Современная наука: актуальные проблемы теории и практики»

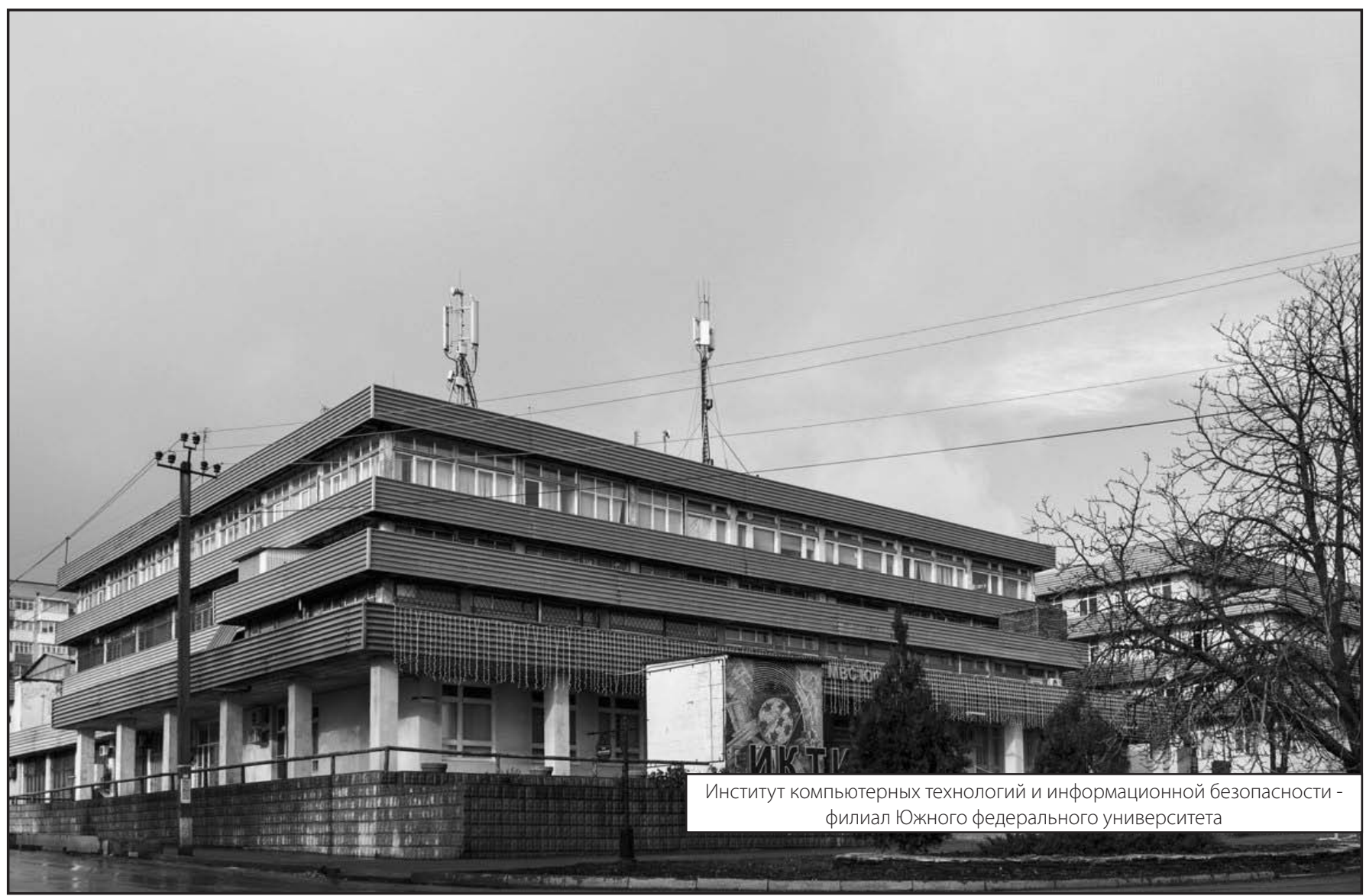

